\title{
Interacting Cracks Analysis Using Finite Element Method
}

\author{
Ruslizam Daud, Ahmad Kamal Ariffin, Shahrum Abdullah and Al Emran Ismail
}

Additional information is available at the end of the chapter

http://dx.doi.org/10.5772/54358

\section{Introduction}

This chapter aims to introduce the concept of fracture mechanics and numerical approaches to solve interacting cracks problems in solid bodies which involves elastic crack interaction. The elastic crack interaction is a result of changes in stress field distribution as the applied force is given during remote loading. The main emphasis is to address the computational evaluation on mechanistic models based on crack tip displacement, stress fields and energy flows for multiple cracks. This chapter start with a brief discussion on fracture and failure that promoted by interacting cracks from industrial cases to bring the issues of how important the crack interaction behaviour is. The present fracture and failure mechanism is assumed to exhibit the brittle fracture. Thus, the concept of linear elastic fracture mechanics (LEFM) is discussed regarding the crack interaction model formulation. As the elastic crack interaction is concerned, the previous analytical and numerical solution of crack interaction are elaborated comprehensively corresponds to fitness-for-service (FFS) as published by ASME boiler and pressure vessel code (Section XI, Articles IWA-3330), JSME fitness-for-service code and BSI PD6493 and BS7910. A new computational fracture mechanics algorithm is developed by adopting stress singularity approach in finite element (FE) formulation. The result of developed approach is discussed based on the crack interaction limit (CIL) aspects and crack unification limit (CUL) in pertinent to the equality of two cracks to single crack rules in FFS. As a conclusion, the FE formulated approach was found to be at agreeable accuracy with analytical formulation and FFS at certain range of crack interval.

\section{Fracture and failures by interacting cracks}

This section provides the overview of failure cases in industries and related fitness-forsevice (FFS) codes which used to assess any cracks or flaws that detected in structures. The works on solution models for FFS codes improvement in specific cases of interacting cracks also discussed. 


\subsection{Industrial failures}

In this section, the fracture and failure by interacting cracks is explained by examples from industrial failures. Mechanical structures and components are designed with multiple stress concentration features (SCF) such as notches, holes, corners and bends. For example, welding and riveting in joining and fastening process have consumed to the increase of stress concentration factor. In every SCF, there is a critical point that experienced the highest concentrated stress field, named as multiple stress riser points (MRSP). Under multiple mode of loading and environmental effect, the interaction between SCF and MRSP tends to form multiple cracks in various types of cracks (e.g. straight crack, surface crack and curved crack) before the cracks propagate in various path to coalescence, overlapping, overlapping, branching and finally fracture in brittle manner.

Crack interaction that induced from MRSP has caused many catastrophic failures, for example in aircraft fuselage (Hu, Liu, \& Barter, 2009), F-18 Hornet bulkhead (Andersson et al., 2009), rotor fault (Sekhtar, 2008), gigantic storage tanks (Chang \& Lin, 2006), oil tankers (Garwood, 2001), polypropylene tank (Lewis \& Weidmann, 2001) and the most recent is the fail of helicopter longerons (J. A. Newman, Baughman, \& Wallace, 2010). The recent lab experimental work on multiple crack initiation, propagation and coalescence by (Park \& Bobet, 2010) and metallurgical work by (J. A. Newman et al., 2010) supported the important role of crack interaction in fracture and failure. The above cases proved how crucial and important the research on crack interaction is.

To explain further, failure in aircraft is considered as an example. Al Alloy has been extensively used for the fabrication of fuselage, wing, empennage, supporting structures that involve many fastening and joining points. Under static, cyclic loading and environmental effect, the micro-cracks are initiated from MRSP. To certain extent, out of many factors, brittle failure may happen through catastrophic failure $(\mathrm{Hu}, \mathrm{Liu}, \&$ Barter, 2009). As the distance between MRSP is close, the interaction between cracks is become more critical. The fracture behavior due to interacting cracks as the distance between cracks is closed need more understanding. The conventional fracture mechanics may be insufficient to support.

In this case, the advancement of computational fracture mechanic may contribute a lot in crack interaction research and increase the accuracy of failure prediction (Andersson et al., 2009). Most recent structural failure being reported is dealing with fuselage joints in large aircraft structures (Hu et al., 2009). The aircraft fuselage structure is made by 7050-T7451 aluminum alloy and designed to have multiple shallow notches that purposely used for lap joints. Due to environmental reaction and variable magnitude of operational loading, multisite cracks are formed at MRSP. Therefore, the interaction of multi-site cracks is needed to be quantified for possible coalescence between cracks. The challenge is how to predict the accurate coalescence and fatigue crack growth for the multiple crack problems. Table 1 provides the list of industrial failures that originated from various kinds of multiple cracks. Under loading condition such as mechanical or thermal loading, it is observed that most of the cracks or flaws formation is start on the surface of the body rather than embedded inside the body. 


\begin{tabular}{|c|c|c|}
\hline Multiple Cracks & Industrial Failures & References \\
\hline Collinear cracks & $\begin{array}{l}\text { Failure of crack arresters- } \\
\text { stiffeners in aircraft structures }\end{array}$ & (Isida, 1973) \\
\hline $\begin{array}{l}\text { Parallel and layered } \\
\text { cracks }\end{array}$ & $\begin{array}{l}\text { Failure of welded-bonded } \\
\text { structures in composite structures } \\
\text { for aircraft }\end{array}$ & (Ratwani \& Gupta, 1974) \\
\hline $\begin{array}{l}\text { Collinear cracks and } \\
\text { edge cracks }\end{array}$ & $\begin{array}{l}\text { Catastrophic fracture accidents of } \\
\text { turbine or generator motor }\end{array}$ & $\begin{array}{l}\text { (Matake \& Imai, 1977; Pant, Singh, \& } \\
\text { Mishra, 2011; Sekhtar, 2008) }\end{array}$ \\
\hline Elliptical cracks & Failure in boilers & $\begin{array}{l}\text { (O'donoghue, Nishioka, \& Atluri, } \\
\text { 1984) }\end{array}$ \\
\hline $\begin{array}{l}\text { Collinear and radial } \\
\text { cracks }\end{array}$ & $\begin{array}{l}\text { Failure of pressurized thick- } \\
\text { walled cylinder }\end{array}$ & $\begin{array}{l}\text { (Chen \& Liu, 1988; Kirkhope, Bell, \& } \\
\text { Kirkhope, 1991) }\end{array}$ \\
\hline $\begin{array}{l}\text { Collinear and micro- } \\
\text { cracks }\end{array}$ & $\begin{array}{l}\text { Failure of ceramic material in heat } \\
\text { exchangers and automobiles }\end{array}$ & (Lam \& Phua, 1991) \\
\hline Parallel cracks & $\begin{array}{l}\text { Failure of aero-engine turbine } \\
\text { engines coatings }\end{array}$ & (Meizoso, Esnaola, \& Perez, 1995) \\
\hline Parallel edge cracks & Failure of actuator piston rods & (Rutti \& Wentzel, 1997) \\
\hline Edge cracks & $\begin{array}{l}\text { Brittle failure of Oil Tanker } \\
\text { structures at welded joints }\end{array}$ & (Garwood, 2001) \\
\hline Array of edge cracks & $\begin{array}{l}\text { Failure of heat-checked gun tubes } \\
\text { and rapidly cooled pressure } \\
\text { vessels }\end{array}$ & (Parker, 1999) \\
\hline $\begin{array}{l}\text { Semi-elliptical } \\
\text { surface cracks }\end{array}$ & $\begin{array}{l}\text { Failure in pressure vessel and } \\
\text { piping components }\end{array}$ & $\begin{array}{l}\text { (Moussa, Bell, \& Tan, 1999; Murakami } \\
\text { \& Nasser, 1982) }\end{array}$ \\
\hline $\begin{array}{l}\text { Collinear cracks and } \\
\text { flat elliptical cracks }\end{array}$ & $\begin{array}{l}\text { Multiple site damage in aircraft } \\
\text { structures }\end{array}$ & $\begin{array}{l}\text { (Gorbatikh \& Kachanov, 2000; Jeong \& } \\
\text { Brewer, 1995; Jones, Peng, \& Pitt, 2002; } \\
\text { Milwater, 2010; Pitt, Jones, \& Atluri, } \\
\text { 1999) }\end{array}$ \\
\hline $\begin{array}{l}\text { Multiple flaws and } \\
\text { surface cracks }\end{array}$ & $\begin{array}{l}\text { Failure of nuclear power plant } \\
\text { components }\end{array}$ & $\begin{array}{l}\text { (Kamaya, Miyokawa, \& Kikuchi, 2010; } \\
\text { Kobayashi \& Kashima, 2000) }\end{array}$ \\
\hline Penny-shaped cracks & $\begin{array}{l}\text { Brittle fracture of welded } \\
\text { structures in pressure vessels }\end{array}$ & (Saha \& Ganguly, 2005) \\
\hline $\begin{array}{l}\text { Offset collinear and } \\
\text { layered cracks }\end{array}$ & $\begin{array}{l}\text { Fracture and catastrophic failure } \\
\text { in polymeric structures }\end{array}$ & $\begin{array}{l}\text { (Lewis \& Weidmann, 2001; Sankar \& } \\
\text { Lesser, 2006; Weidmann \& Lewis, } \\
\text { 2001) }\end{array}$ \\
\hline Interface cracks & $\begin{array}{l}\text { Failure in electronic packages and } \\
\text { micro-electro-mechanical systems } \\
\text { (MEMS) }\end{array}$ & $\begin{array}{l}\text { (Ikeda, Nagai, Yamanaga, \& Miyazaki, } \\
\text { 2006) }\end{array}$ \\
\hline Parallel cracks & $\begin{array}{l}\text { Fracture in functional gradient } \\
\text { materials (FGM) }\end{array}$ & (Yang, 2009) \\
\hline $\begin{array}{l}\text { Short cracks and } \\
\text { micro-cracks }\end{array}$ & Fracture in bones & $\begin{array}{l}\text { (Lakes, Nakamura, Behiri, \& Bonfield, } \\
\text { 1990; Mischinski \& Mural, 2011; Ural, } \\
\text { Zioupos, Buchanan, \& Vashishth, } \\
\text { 2011) }\end{array}$ \\
\hline
\end{tabular}

Table 1. Summary of industrial failures caused by multiple crack interaction 
Crack interaction intensity exist in the form of stress shielding and amplification. The failure mechanism by cracks interaction may occurs under brittle, plastic and creep failure. In general, the interacting cracks problems that promotes the fracture and failure of structures are solved using the advancement of fracture mechanics. The fracture mechanics solution can be accomplished through analytical, numerical and experimental work. Based on the above individual approach or combination of them, typically the solution is represented by a model. The model may be defined based on the uncertainty input for the model such as crack geometry, loading and material properties. For crack interaction problems that randomness is relatively small, the deterministic analysis is the best to considered rather than probabilistic analysis. The model is suitable for any deterministic system response. However, when the randomness is relatively high, the model system response required a more robust solution, known as probabilistic approach.

Multiple cracks interaction can be defined into elastic crack interaction and plastic crack interaction that may be referred to theory of elasticity and plasticity, respectively. Under loading condition, the high stresses near crack tips usually accompanied by inelastic deformation and other non-linear effect. If the inelastic deformation and other non-linear effect are relatively small compared to crack sizes and other geometrical body characteristic, the linear theory is most adequate to address the crack interaction behavioral problems. Thus, the role of elastic driving force originated from crack tips can be translated into elastic crack interaction. Then, for every type of interaction, it may classified into interaction without crack propagation (EIWO) where the interaction occurs in the region of SIF $K<K_{c}$ and interaction with crack propagation (EIWI) occurs in the region of SIF $K \geq K_{c}$. In this case of EIWO, the quantification of crack extension is neglected. The EIWO becomes the main issue of interaction in present study since it is inadequate investigation on crack interaction limit and multiple to single crack equivalencies. The study on EIWO is typically measured the fracture parameter and its behavior based on SIF while EIWI more focused to evaluation and prediction of crack path, propagation, coalescence, branching and crack arrestment. Under mechanical or thermal loading condition, the generated interaction will varies depends on type of loading mode (e.g. Mode I and Mode II) being applied. The preceding sections outlined the related fitness-for-service (FFS) codes in pertinent to failures that caused by crack interaction.

\subsection{Fitness-for-Service (FFS) codes}

This section presents the guidelinea that have been published in fitness-for-service (FFS) codes. The related investigation works also discussed as the FFS codes are evaluated in different case of interacting cracks problems. ASME Boiler and Pressure Vessel Code Section XI (ASME, 1998, 2004) and API 579 (ASME, 2007) defines that the multiple cracks are assumed to be independent until or unless the following conditions are satisfied. In the case of two parallel cracks in solid bodies, if distance between crack planes $d \quad d \leq 12.7 \mathrm{~mm}$, the cracks are treated as being coplanar. For coplanar cracks, if the distance between cracks $s$ $s \leq 2 \times\left(\right.$ maximum of $\left.\left\{a_{i}\right\}_{i=1,2}\right)$. Indeed, the single enveloping crack is assumed equal to 
coplanar cracks if the condition of crack depth $a$ and surface length $c$ satisfy $a=$ maximum of $\left\{a_{i}\right\}_{i=1,2}, c=c_{1}+c_{2}+s / 2$. If the non-coplanar cracks in overlapped condition at $s<0$, the cracks are assumed to be coplanar, the surface length $c$ $c_{\text {new }}=c_{1}+c_{2}+s$. Thus, coalescence occur at $s=\max \left(2 a_{1}, 2 a_{1}\right)$. In United Kingdom, the engineering critical assessment (ECA) of potential or actual defects in engineering structures is codified into two prime standard; British Standard PD6495 (BSI, 1991) and Nuclear Electric CEGB R6 (R6, 2006). BSI PD6495 has replaced by BS7910 (BSI, 1997), and most latest (BSI, 2005). Original BSI PD6495 primarily concerned on assessment of defect welds. The PD 6495 used crack tip open displacement (CTOD) and SIF $K$ based analysis while the BS7910 used CTOD, $K$ or equivalent $K$ that derived from $J$-integral. Both codes define the cracks are assumed to be independent until or unless the following distance between crack planes $d$ satisfy $d \leq 0.5\left(a_{1}+a_{2}\right)$ and the cracks are treated as being coplanar. For coplanar cracks, if the distance between cracks $s s \leq 2 \times\left(\right.$ minimum of $\left.\left\{c_{i}\right\}_{i=1,2}\right)$, a single enveloping crack is assumed and the coalescence occur at $s=0.5\left(2 c_{1}+2 c_{2}\right)$. The R6 is an approach to upgrade the BSI PD6495 by Central Electricity Generating Board (CEGB) that focused on operating equipment at high temperature where the assumption of equal or greater fracture and possibility of plastic collapse together and fracture separately. The concept of failure assessment diagram (FAD) is introduced to occupy the need of fracture parameter of plasticity fracture. R6 provides a special form of J-integral analysis to impose the plastic collapse limit. Details of FAD can be found in (R6, 2006). JSME Fitness-for-Service Code provides no prescription for the interference between multiple cracks or flaws. In (JSME, 2000), in example of parallel offset cracks, the multiple cracks are replaced by an equivalent single crack based on the stage of detected cracks with satisfying the condition of $S \leq 5 \mathrm{~mm}(H \leq 10 \mathrm{~mm})$ and $S>5 \mathrm{~mm}(H<2 S)$ where $S$ is relative vertical spacing and $H$ is relative horizontal spacing. When the crack tips distance $S \leq 0$ due to overlapped condition, the crack growth evaluation is considered about the coalescence stages. The guideline in JSME Code is based on experimental results. In (JSME, 2008), the interacting cracks are combined in crack growth prediction and the judgment is based on the relative spacing $S$ and $H$ at the initial condition. If the relative spacing at the beginning of the growth prediction meets the criterion, two cracks are combined when the distance $S$ become zero during the crack growth.

\subsection{Interacting cracks models for Fitness-for-Service}

The solution for interacting surface or embedded cracks that based on FFS revision is limited in literature especially for interacting parallel edge cracks in finite body. Therefore, a review on available developed technique or models that related to FFS is presented in this section. The need of continues revision on FFS limitations based on ASME Boiler and Pressure Vessel Code Section XI and British Standard BS7910 started by the industrial failures in all major pressure vessels (Burdekin, 1982). The pressure vessels are designed and built to comply with ASME Boiler and Pressure Vessel Code Section XI and British Standard BS7910 codes but the failure occurrences are significantly high. Both codes can be expressed as 
$\begin{array}{ll}\text { ASME } & s \leq 2 \times\left(\text { maximum of }\left\{a_{1}, a_{2}\right\}\right) \\ \text { BSIPD6493 } & s \leq 2 \times\left(\text { maximum of }\left\{c_{1}, c_{2}\right\}\right)\end{array}$

To investigate the problem, (Burdekin, 1982) studied the interaction between the collapse and fracture in pressure vessels using the approach that successfully applied to nuclear applications. The approach applied the LEFM and EPFM using COD and J-integral based on single crack under bending condition. The study revealed the important of fracture mechanics as a tool for interaction in failures. This work can be considered as among the first work that put concern on the FFS codes.

Similarly, (O'donoghue et al., 1984) investigated the formation of elliptical cracks in aircraft and pressure vessel attachment lugs and identified the formation is due to stress risers and cracks interaction. Two equal coplanar surface cracks under Mode I loading are modeled using the proposed finite element alternating method (FEAM) in finite solid and the FE analysis results are compared to ASME Boiler and Pressure Vessel Code procedure. The interaction effects are defined by proposed magnification factor (normalized SIF) and the magnification factors seem to increase due to the increase interaction of two cracks and the depth of cracks. The Section XI of ASME Boiler and Pressure Vessel Code recommend that two interacting surface flaws in a pressure vessel should be modeled by a single elliptical crack that covers both flaws. It can be seen that SIF for single crack as proposed by FFS code are generally larger than those due to two interacting cracks as proposed by (O'donoghue et al., 1984). This trend of magnification factor shows that the ASME Boiler and Pressure Vessel Code in Section XI procedure will tend to underestimate the design life of multiple flaws structures. The ASME pressure vessel codes (ASME, 1998) and British Standard PD6495 (BSI, 1991) do not quantify the interaction between cracks especially in two close proximity cracks. At sufficiently close distance, the interaction may cause the increase of SIF. The exclusion of crack interaction may result with unrealistic SIF. Therefore, with the concern on the above standard guideline, (Leek \& Howard, 1994) presents an empirical method to approximate the interaction factor of two coplanar surface cracks under tension and bending loading. The approximation approach resulted with good agreement with FE analysis using developed BERSAFE program, (Murakami \& Nasser, 1982) and (J. C. Newman \& Raju, 1981) within $\pm 5 \%$ discrepancy.

$$
\begin{gathered}
a=\text { maximum of }\left\{a_{i}\right\}_{i=1,2}, c=c_{1}+c_{2} \\
(s / \bar{c}) \times(s / \bar{a})>3.38 \text { and } s / \bar{a} \geq 2.49
\end{gathered}
$$

Based on the (ASME, 2004) and (BSI, 1991) design code that expressed by Eq. (1), (Moussa et al., 1999) used FEM to analyze interaction of two identical parallel non-coplanar surface cracks subjected to remote tension and pure bending loads. The interaction factor as a function of stress shielding to cause overlapping in distance is studied using three dimensional linear finite element analyses. The formation of stress relaxation state is introduced near crack front, as a form of shielding effect at sufficient overlapping. J-integral is calculated based on models by (Shivakumar \& Raju, 1992) and the interaction factor $\gamma$ is defined as follows: 


$$
\gamma=K_{\text {in }} / K_{\text {is }}
$$

where $K_{i n}$ and $K_{i s}$ are the SIFs with and without the influence of interaction, respectively. As conclusion, the interaction effect appears to diminish as the value of $s / c$ approaches 2.0. The existing rules for re-characterization of interacting cracks as less conservative for high values of $s / c$ and over-conservative as $s / c$ is close to 2.0.

The existing (ASME, 1998; JSME, 2000) FFS combination rules provided no prescription for the interference between multiple cracks for corrosion fatigue. Therefore, (Kamaya, 2003) developed simulation model to extent the condition of coalescence rules in (JSME, 2000) for crack growth process using body force method (BFM). BFM is used to investigate the multiple cracks growth in stress corrosion cracking. Based on JSME code and the SIF value of coalescence behavior from experiments, the new SIF formulation is developed using BFM where focus is given to the interaction between cracks under various relative position and size. The crack propagation direction can be written as

$$
\theta_{\max }=\mp \cos ^{-1}\left(\left(3 K_{I I}^{2}+K_{I} \sqrt{8 K_{I I}^{2}+K_{I}^{2}}\right) /\left(9 K_{I I}^{2}+K_{I}^{2}\right)\right)
$$

where the sign in Eq. (5) positive in the case of $K_{I I} / K_{I}<0$ and negative in the case of $K_{I I} / K_{I}>0$. When the crack are close and overlapped, the crack interaction intensity between cracks is almost equivalent to single coalesced crack. The change of inner crack tips direction also found with little influence on the crack growth behavior. The relative crack length and position influenced the crack interaction intensity.

The combination rule in ASME Code is found to provide the relative large overestimation of the actual crack growth since the complex growth phenomena under interaction are summarized in simple combination rules. In order to reduce the conservativeness in existing code, (Kamaya, 2008b) proposed alternative assessment procedures based on the size of area and fatigue crack growth. Experimental analysis and testing is conducted using stainless steel specimens (A-H0S5 and B-H0S5) subjected to cyclic tensile loading. FE analysis is carried out to simulate the crack growth during coalescence. In the simulation, the automatic meshing was generated by command language in PATRAN and the SIF is derived from energy release rate obtained from virtual crack extension integral method using ABAQUS. The normalized SIF of Mode I, $K_{I}$ is expresses as

$$
F_{I}=K_{I} / \sigma_{0} \sqrt{\pi a}
$$

where $\sigma_{o}$ denotes the applied tensile stress and the $a$ is the maximum depth. As a result, the area of the crack face is concluded to be the predominant parameter for the crack growth of interacting cracks under test condition. The cracks of various shapes can be characterized as semi-elliptical cracks of the same area. In extension of parallel semi-elliptical cracks study, (Kamaya, 2008a) investigated the coalescence of adjacent cracks as a result of crack growth 
with the influence of crack interaction. The magnitude of interaction is represented by driving force of the crack growth (CGF), written as

$$
W_{m}=\sum_{i=1}^{n-1} 0.5\left(D_{p} K_{I(i)}^{m_{p}}+D_{p} K_{I(i+1)}^{m_{p}}\right) \Delta g
$$

where $D_{p}$ and $m_{p}$ are the material constant, $K_{I(i)}$ denotes the Mode I SIF of the $i$ th node from $p=0^{\circ} . \Delta g$ and $n$ are the distance of neighboring mode on the crack front and number of nodes. The CGF formulation proved that the interaction between surface cracks not only dependent on relative spacing but also the position of crack front. In the condition of $S>0$, as the cracks overlapped, the stress shielding effect influenced the change of CGF. The most important, the study notified the cracks can be replaced with single crack of the same area when the relative spacing is sufficiently close, at crack spacing $H<a$. In regular inspection of pressure vessel components, the adjacent defects are found close enough. Under operational loading, the stress field around the crack tips will be magnified and accelerates the crack growth rate. This matter has been referred to current fitness-for-service (FFS) rules such as ASME Boiler and Pressure Vessel Code Section XI (ASME, 1998, 2004), API 579 (ASME, 2007), British Standard PD6495 (BSI, 1991), BS7910 (BSI, 1997, 2005) and Nuclear Electric CEGB R6 (R6, 2006). The multiple interacting cracks are combined as single crack as the two cracks satisfy the prescribed criterion. As observed, this rule introduced unrealistic discontinuity in the process of crack growth due to the crack interaction is neglected. The evaluation of two interacting coplanar cracks in plates under tension is conducted by (Xuan, $\mathrm{Si}, \& \mathrm{Tu}, 2009$ ) and creep interaction factor $\gamma_{\text {creep }}$ is introduced by using $C^{*}$ integral prediction analysis and the FE analysis is executed using ABAQUS to verify the proposed approach. Creep interaction factor $\gamma_{\text {creep }}$ is expressed as

$$
\gamma_{\text {creep }}=\left(C_{\text {Double }}^{*} / C_{\text {Single }}^{*}\right)^{1 / 2}
$$

In conclusion, the creep crack interaction represented by $C^{*}$ integral is affected by crack configuration (e.g. relative crack distance $c / d$, depth of crack a/t and location at crack front $2 \varnothing / \pi)$ and time dependent properties of material such as creep exponent $n$. The increasing crack aspect $a / c$ resulted with no significant effect to $C^{*}$ integral.

Most recent, (Kamaya et al., 2010) used S-version finite element method to determine the SIF changes due to the interaction of stress field which caused variation in crack growth rate and cracks shape. The root of interaction problems is referred to (JSME, 2000, 2008) and (ASME, 2004, 2007) for the case of interacting dissimilar crack sizes. However, the effect of difference crack size or relative size effect is not taken into account in the aforementioned code. The results have shown that smaller cracks stopped growing when the difference in size of interaction was large enough. It means, the interaction effect on the fatigue life of the larger cracks was negligibly small. Moreover, the offset distance and the relative size were 
important parameter for interaction evaluation especially when the $S=0$ and the condition of crack spacing $H / c_{1}$ and cracks ratio $c_{2} / c_{1}$ must be considered most. In present study, the focus is given to determine the stage of crack interaction intensity is equal to single crack in a state of crack interaction limit (CIL) and unification (CUL) using finite element method.

\section{Finite element analysis}

\subsection{Finite element analysis}

The stress in the neighborhood of a crack tip in homogenous isotropic material exist in a form of square-root singular and there have been many special elements or singularity function based approach were described in details in (Banks-Sills, 1991). The square root singular stresses in the neighborhood can be modeled by quarter-point, square and collapsed, triangular elements for two dimensional problems, and by brick and collapsed, prismatic elements in three dimensions. Quarter-points square have been found to produce the most excellent results (Banks-Sills, 2010). The stiffness matrix of the element is evaluated using two-dimensional integral based on Gaussian quadrature approach. The plate is constructed with a consideration of singular element and assigned to both crack tips $C t_{1}$ and $\mathrm{Ct}_{2}$. It is because the high gradients of singular stress-strain and deformation fields are concentrated at both crack tips. The SIF calculation is limited to linear elastic problem with a homogeneous, isotropic material near the crack region.

\subsubsection{Singularity stress field}

The studies are conducted in a pure Mode I loading condition with specified material, Alloy 7475 T7351 solid plate in constant thickness, homogenous isotropic continuum material, linear elastic behavior, small strain and displacements, and crack surface are smooth. According to Westergaard method for single crack, Mode I $K_{I}$ and Mode II $K_{I I}$ SIF can be expressed as:

$$
\begin{aligned}
& K_{I}=F / K_{o}=F(b / a, a / W) \sigma_{o} \sqrt{\pi a} \\
& K_{I I}=F / K_{o}=F(b / a, a / W) \tau_{o} \sqrt{\pi a}
\end{aligned}
$$

where $\sigma_{o}$ is nominal stress, $\tau_{o}$ is shear stress, $W$ is width of specimen, $a$ and $b$ is the length of crack and crack interval, respectively. The work starts by determination of $K_{I}$ and $K_{I I}$ using Eq. (9). The important issue which differs from single crack is the existence of cracks interaction in fracture analysis.

Consider two multiple edge crack of length $a_{1}$ and $a_{2}$ which occupies the segment of $0.05 \leq$ $a / W \leq 0.5$ and $0.5 \leq b / a \leq 3.0$ in finite plate subjected to uniform equal stress $\sigma$ along the $y$ direction, as shown in Fig. 1(a) and (b). The SIF formulation is based on the creation of singular element at the crack tip based on quadratic isoparametric finite element developed in ANSYS evironment based on (Madenci \& Guven, 2006), where the element is based on Barsoum (Barsoum, 1974, 1975), as depicted in Fig. 2 (a) and (b). The singularity is obtained 
by shifting the mid-side node the $1 / 4$ point close to the crack tip. To calculate the SIF, the elements are assumed to be in rigid body motion and constant strain modes. The master element mapping in Cartesian space is transformed into curvilinear space using Jacobian transformation which used to interpolate the displacement within the elements (Chandrupatla \& Belegundu, 2002). The accuracy of special element has been addressed by (Murakami, 1976) where the crack tip nodal point is enclosed by a number of special element. In analysis, the size, number and compatibility of special elements really affect the accuracy. The special elements also defined as singularity function methods where stress singularity at crack tip is modeled. The condition of continuity between elements is the most important. By using singularity function method, Mode I and Mode II of stress intensity factor may be able to calculate with high accuracy (Shields, Srivatsan, \& Padovan, 1992).

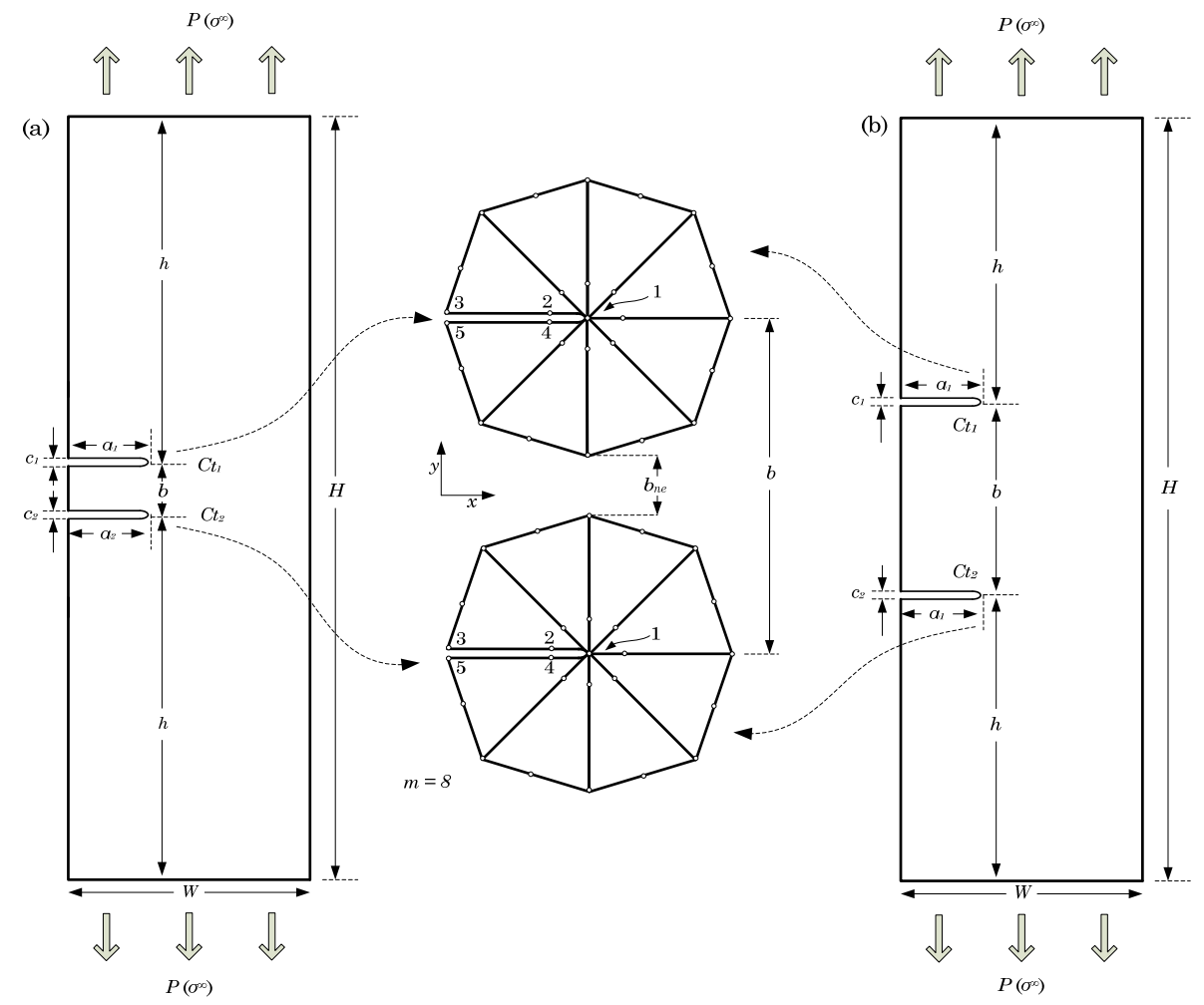

Figure 1. Barsoum singular element for (a) strong crack interaction and (b) weak crack interaction

According to Eq. (9), the shape correction factor can be converted to new elastic interaction factor

$$
\begin{aligned}
& \gamma_{I, i n, D}=K_{I} / K_{o} \\
& \gamma_{I I, i n, D}=K_{I I} / K_{o}
\end{aligned}
$$


where $\gamma_{I}$ and $\gamma_{I I}$ denotes to elastic interaction factor for Mode I and II fracture, respectively.

The SIF for Mode I and Mode II is determined using Displacement Extrapolation Method (DEM) by written APDL macro code in ANSYS (Madenci \& Guven, 2006), and expressed as

$$
\begin{aligned}
& K_{I}=\frac{E}{3(1+v)(1+\kappa)} \sqrt{\frac{2 \pi}{L}}\left(4\left(v_{2}-v_{4}\right)-\frac{\left(v_{3}-v_{5}\right)}{2}\right) \\
& K_{I I}=\frac{E}{3(1+v)(1+\kappa)} \sqrt{\frac{2 \pi}{L}}\left(4\left(u_{2}-u_{4}\right)-\frac{\left(u_{3}-u_{5}\right)}{2}\right)
\end{aligned}
$$

where, $E=$ Young Modulus, $\kappa=3-4 v$ for plain stress, $\kappa=3-4 v / 1-v$ for plain strain, $L$ is length of element, $v$ and $u$ are displacements in a local Cartesian coordinate system and $v$ is Poisson's ratio.

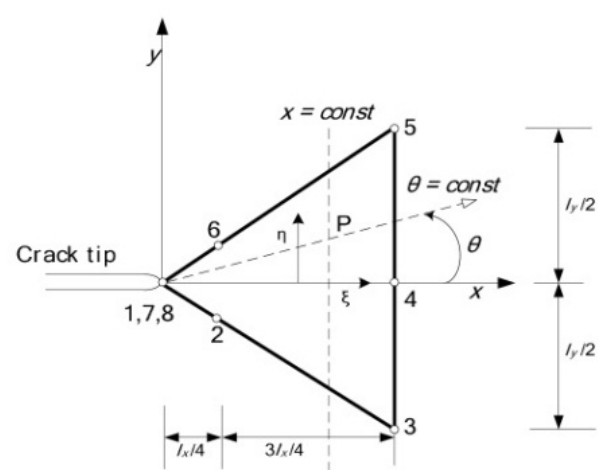

(a)

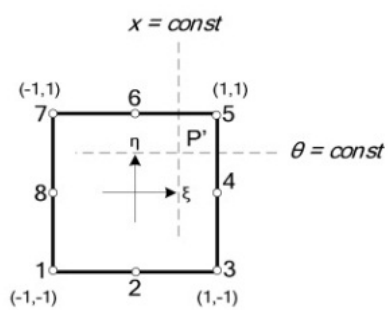

(b)

Source: (Barsoum, 1974, 1976; Henshell \& Shaw, 1975)

Figure 2. (a) Eight nodes quadratic isoparametric elements (b) Parent element

\section{Findings and discussion}

Two parallel edge cracks interaction will mainly referred to shielding effect rather than amplification effect. The crack interaction is proportional to the magnitude of elastic interaction factor $\gamma_{I}$. The crack interaction will only exist at $b / a<3$ (Z.D.Jiang, A.Zeghloul, G.Bezine, \& J.Petit, 1990; Z.D.Jiang, J.Petit, \& G.Bezine, 1990), the analytical formulation can be expressed as

$$
K_{I}=K_{o} F_{n}(a / W, b / a)
$$

in which 


$$
\begin{aligned}
& \gamma_{I, \text { in }, J i}=F_{n}=F_{2}=\frac{A_{0}+A_{1}(a / w)^{1.5}+A_{2}(a / w)^{4}}{\sqrt{1-(a / w)^{2}}} \\
& A_{0}=0.79+0.07(b / a)+0.04(b / a)^{2}-0.011(b / a)^{3} \\
& A_{1}=1.74+2.84(b / a)-1.44(b / a)^{2}+0.206(b / a)^{3} \\
& A_{2}=6.02+2.19(b / a)-3.26(b / a)^{2}+0.828(b / a)^{3}
\end{aligned}
$$

and analytical single edge crack SIF reference by (Brown \& Strawley, 1966),

$$
\begin{aligned}
& K_{I, \text { ref }}=\sigma_{0} \sqrt{\pi a}\left(1.12-0.23(a / W)+10.6(a / W)^{2}-21.7(a / W)^{3}+30.4(a / W)^{4}\right) \\
& K_{I, \text { ref }}=\sigma_{0} \sqrt{\pi a}\left(f_{I, \text { ref }, B S}\right)
\end{aligned}
$$

\subsection{Crack interaction factor $\gamma_{I, i n, D}$ comparison with analytical data $\gamma_{I, i n, J i}$}

The mode I fracture of the elastic interaction factors $\gamma_{I, i n, D}\left(\gamma_{I, i n, D, c t 1}, \gamma_{I, i n, D, c t 2}\right)$ for crack interval ratio $b / a=1.5-3.0$ and $a / W=0.05-0.5$ are shown in Fig. 3-6. Overall, it can be seen that the interaction factor varies with the different $a / W$ values where the crack interaction factor increases as the $a / W$ increases and vice versa. The point of intersection also observed occurred for all the $b / a$ values. For example, the plot of $\gamma_{I, i n, D}\left(\gamma_{I, i n, D, c t 1}, \gamma_{I, i n, D, c t 2}\right)$ against $a / W$ at $b / a=3.0$ are illustrated in Fig. 3.

The $\gamma_{I, i n, D}$ prediction line is compared with the predicted result of single edge crack $f_{I, r e f, B S}$. A general good agreement can be observed with a minimum difference $0.6 \%$ at $a / W=0.1$ and maximum difference $5.39 \%$ difference $a / W=0.15$. In comparison, the present $\gamma_{I, i n, D}$ has demonstrated more accurate prediction compared with $\gamma_{I, i n, J i}$ results. For example, in reference to $f_{I, r e f, B S}$, at $a / W=0.5$, the present prediction $\gamma_{I, i n, D}$ is in difference of $\gamma_{I, i n, D, c t 1} 0.85 \%$ and $\gamma_{I, i n, D, c t 2} 0.4 \%$, while $\gamma_{I, i n, j i}$ is at $2.15 \%$ difference. In terms of the CIL point, the closer the crack interaction to $f_{I, r e f, B S}$ of single crack, a more accurate CIL prediction can be achieved. It is noted that the $\gamma_{I, i n, J i}$ analytical expression was formulated using the numerical results of J-integral analysis. The formulation is unable to calculate the crack interaction factor for both crack tips and become the weakness of $\gamma_{I, i n, J i}$. Therefore, the present work of DEM has improved the existing J-integral analysis by improving the accuracy of CIL to predict fracture due to crack interaction.

Theoretically, the study of intersection point is most significant in identification of crack interaction limit (CIL) and crack unification limit (CUL). The intersection point of two cracks $\gamma_{I, i n, D}$ with single crack $f_{I, \text { ref,BS }}$ justifies the realization of CIL at higher $a / W$ and CUL at 
lower $a / W$. The CIL and CUL also differ with different $b / a$. From Fig. 3, the identified CUL is at $a / W=0.1$ and CIL approximately at $a / W=0.5$.

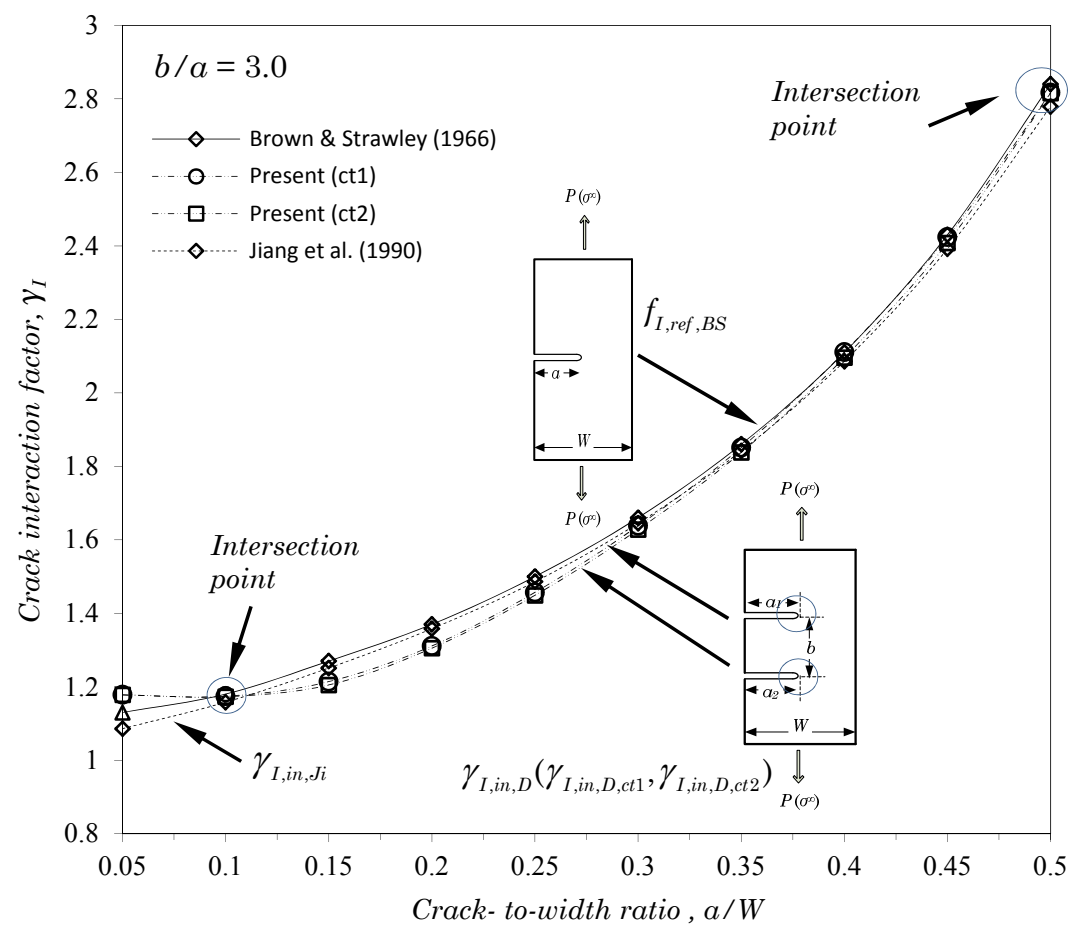

Figure 3. Variation of $\gamma_{I, i n, D}$ against $a / W$ for $b / a=3.0$

Another significant improvement of present $\gamma_{I, i n, D}$ is the moving intersection point as $a / W$ decreases for every $b / a$, as shown in Fig. 3-6. From Fig. 4 , the moving intersection point can be noticed moves from $a / W=0.1$ to $a / W=0.075$. The moving intersection point exhibits similar prediction trend of $\gamma_{I, i n, D}$. The intersection point also can be denoted as the crack unification limit (CUL) point, which indicates the starting point of strong interaction region start approximately at $a / W<0.07$.

The intersection point is also observed to move from $a / W=0.075$ for $b / a=2.5$, $a / W=0.06$ for $b / a=2.5, a / W=0.05$ for $b / a=2.0$ and $a / W<0.05$ for $b / a=1.5$, as shown in Fig. 4-6. It means that the CUL is not in a fix limit, it exist in dynamic condition which depends on crack interval ratio $b / a$. Conversely, the $\gamma_{I, i n, J i}$ prediction model overruled the FFS codes because it does not lead to a single independent or combined crack because of not having any intersection point. The intersection point could not be defined by $\gamma_{I, i n, J i}$ prediction model. 


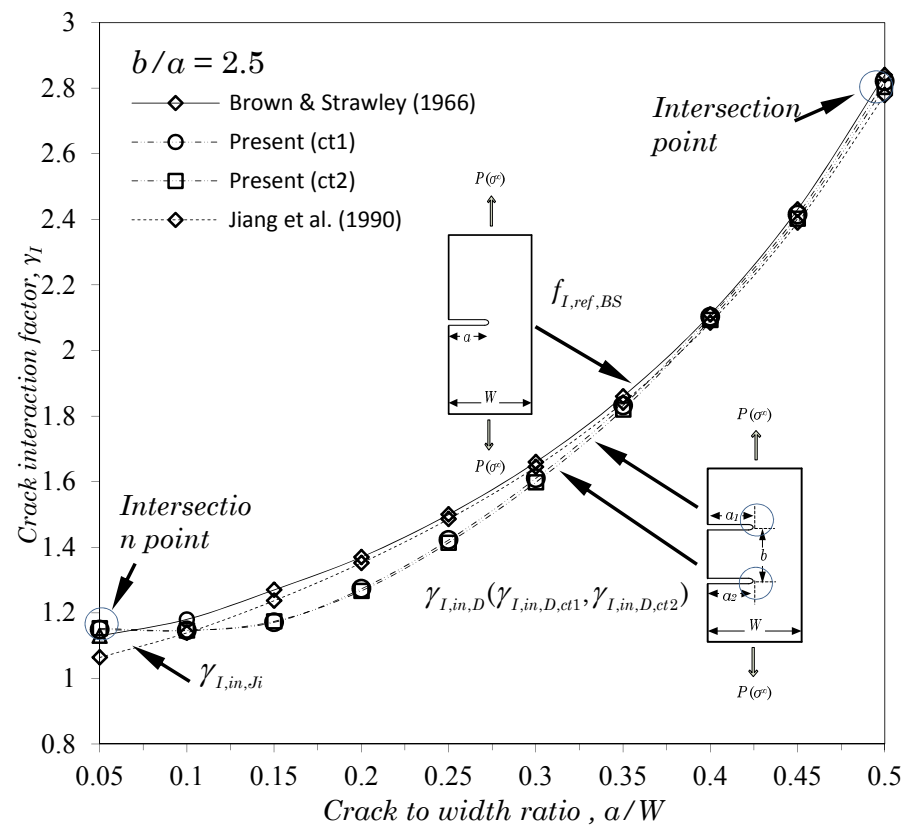

Figure 4. Variation of $\gamma_{I, i n, D}$ against $a / W$ for $b / a=2.5$

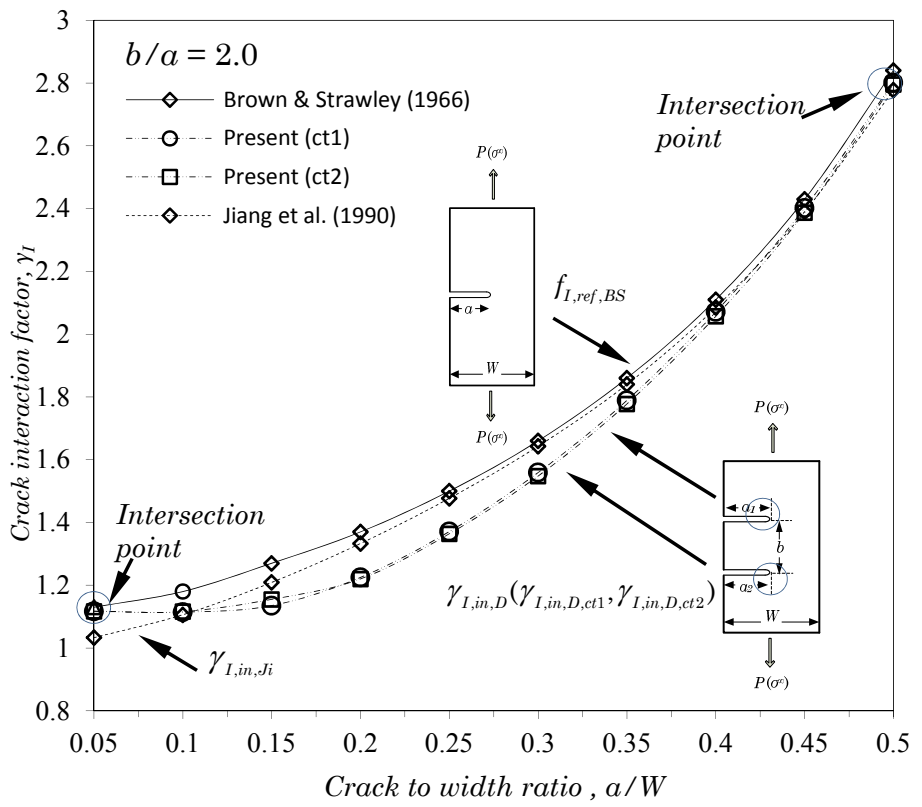

Figure 5. Variation of $\gamma_{I, i n, D}$ against $a / W$ for $b / a=2.0$ 
It also can be seen that $\gamma_{I, i n, J i}$ prediction is unable to display the unification of crack interaction factor, which defined equivalent to $f_{I, r e f, B S}$ of single crack. In this case, the $\gamma_{I, i n, J i}$ prediction is expected to encounter some numerical errors since at lower $a / W<0.07$. In analysis, the ratio of crack length and width also define the critical stress field, if the path independent radius of $J$-integral for both crack tips are overlapped, the calculation of $J$ value might be overestimated and the stress behavior is equal to behavior of single edge crack in finite body. The path integral line should be always apart and controlled in individual condition.

Based on the FFS codes, the multiple cracks are assumed to be independent as single cracks or combined cracks, until or unless certain conditions are satisfied. The intersection point that lies in the present $\gamma_{I, i n, D}$ prediction trend curve, which intersects with the single crack prediction, shows good agreement with the outlined FFS codes. It is seen that at range of $0.05 \leq a / W \leq 0.15$, the $\gamma_{I, i n, D}$ value is about to level at $1.072-1.085$. The small changes in these range indicate that shielding effect is very small and promote the unification in interaction at the point of $a / W=0.15$. The smaller the $b / a$, the faster unification process starts.

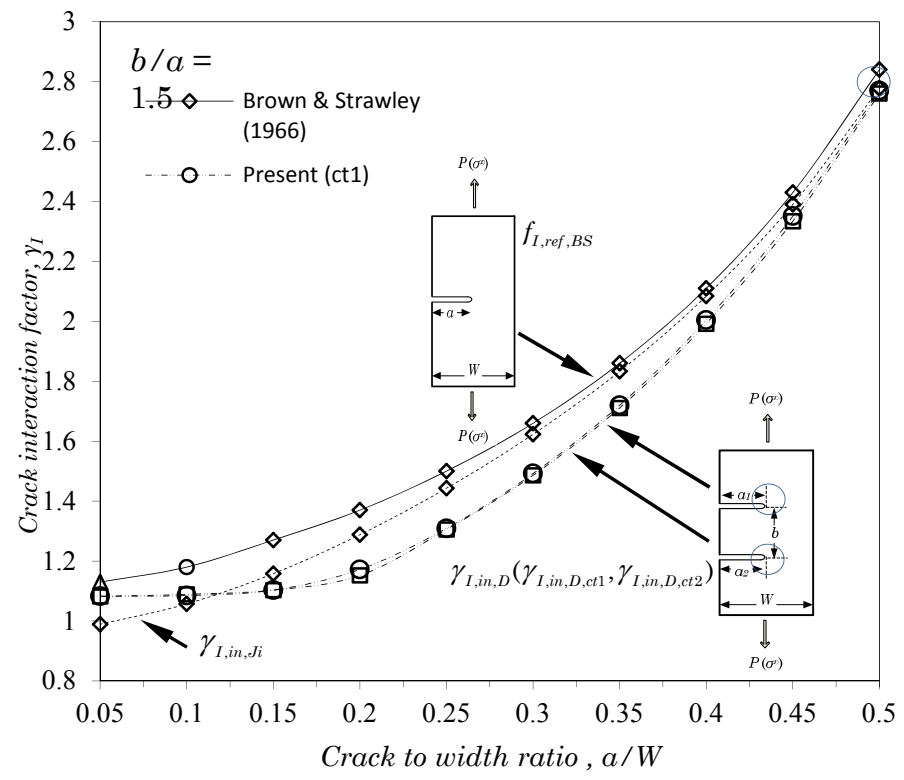

Figure 6. Variation of $\gamma_{I, i n, D}$ against $a / W$ for $b / a=1.5$

\subsection{Mode II fracture behavior}

Fig. 7 depicts the trend of $K_{I, i n, D}$ and $K_{I I, i n, D}$ against $b / a$ for $a / W=0.25-0.5$. It can be seen that the increase in $b / a$ results in an increase of $K_{I, i n, D}$ and a decrease of $K_{I I, i n, D}$ 
(a)

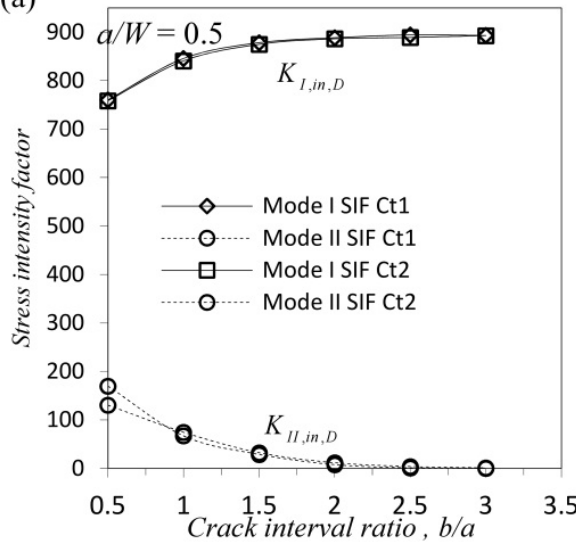

(b)

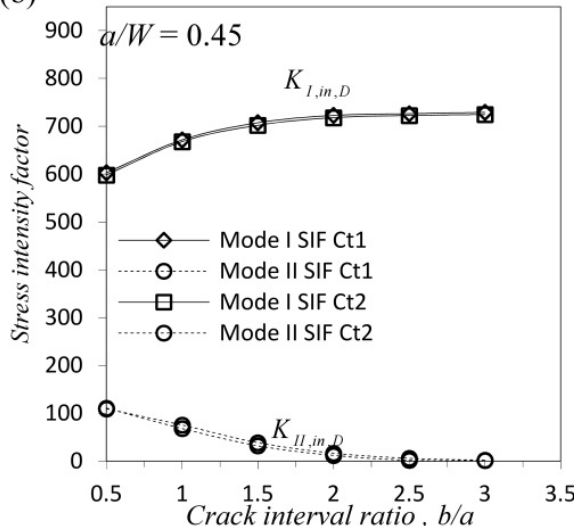

(c)

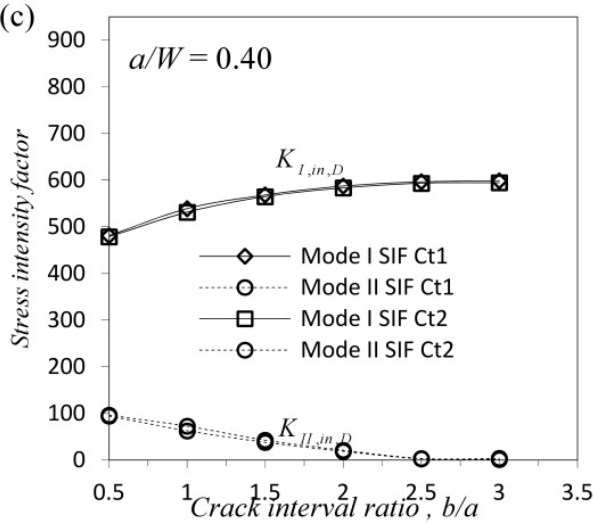

(d)

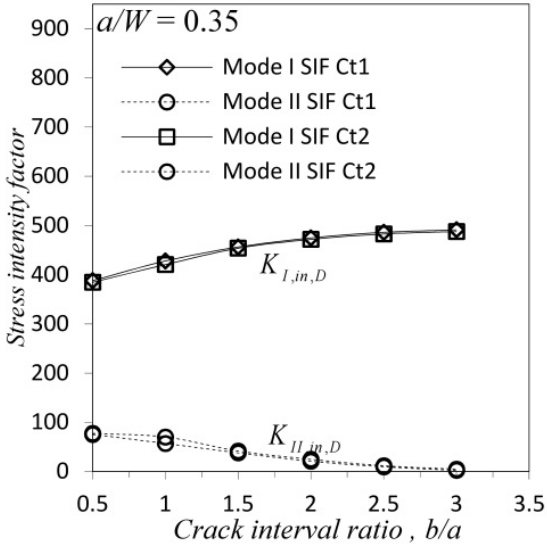

(e)

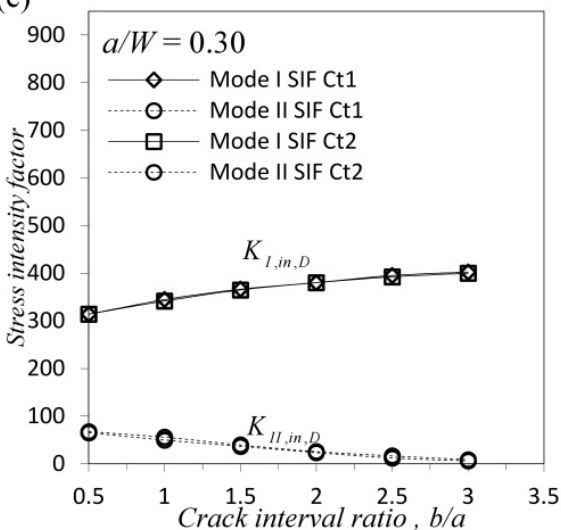

(f)

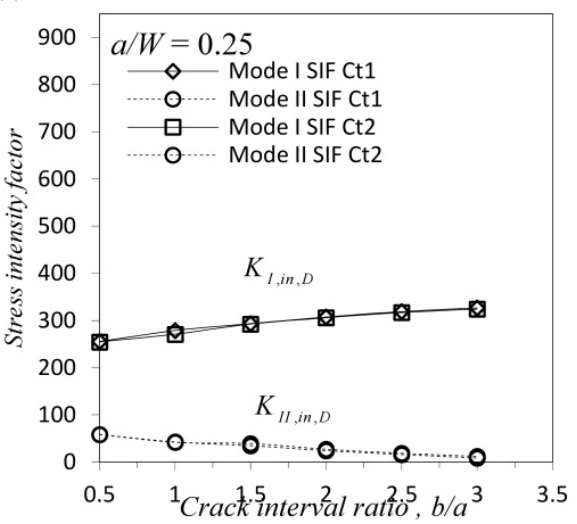

Figure 7. Variation of $K_{I, i n, D}$ and $K_{I I, i n, D}$ for $(a / W=0.25-0.5)$ 
values. In strong interaction region $0 \leq b / a \leq 1.0$, the values of $K_{I, i n, D}$ increased rapidly for higher crack-to-width ratio $a / W=0.5,0.45$ and before grew slowly as the value of $a / W$ decreases to $a / W=0.25$. Meanwhile, the values of $K_{I I, i n, D}$ declined significantly at higher crack-to-width ratio $a / W=0.5,0.45$ and before decreased slightly as the value of $a / W$ decreases to $a / W=0.25$. For both crack interaction phase, the value of $K_{I, i n, D}$ is always much higher than $K_{I I, i n, D}$. In weak interaction region $1.5 \leq b / a \leq 3.0$, it can be seen that the values of $K_{I, i n, D}$ increased slightly before growing slowly and then maintaining at the same level to steady state at $b / a=3.0$. At the same region, the value of $K_{I I, i n, D}$ declined moderately before decreased slightly and remain stable at the level of $b / a=3.0$. It means that mode II SIF is less influenced by damage shielding effect than mode I SIF. It also defined that the crack opening is more affected by damage shielding effect than the crack sliding. This has been clearly indicated in Fig. 7 (a)-(f) and Fig. 8(a)-(d).
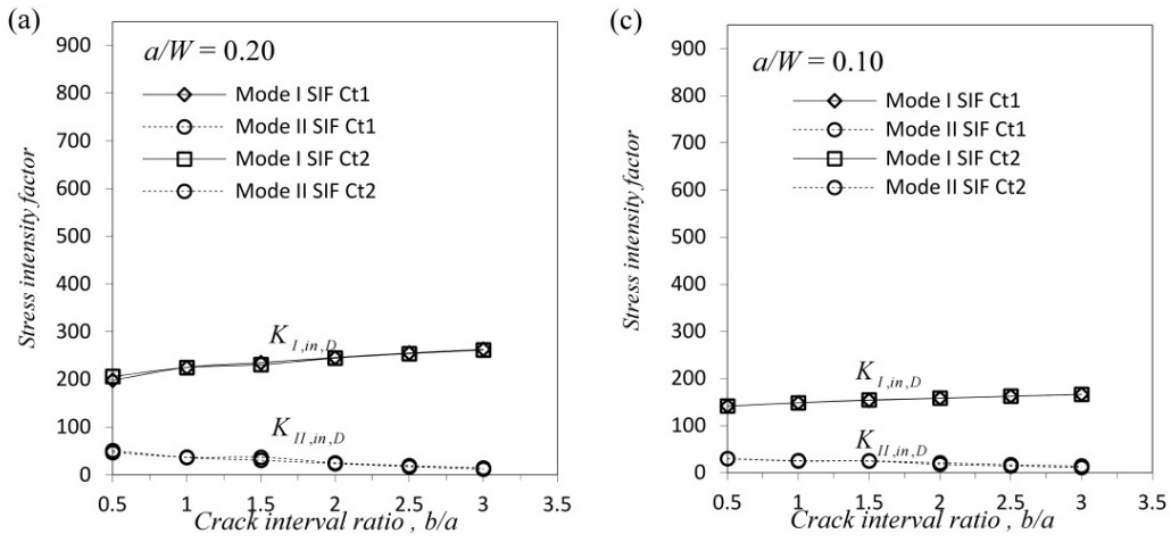

(b)

(d)
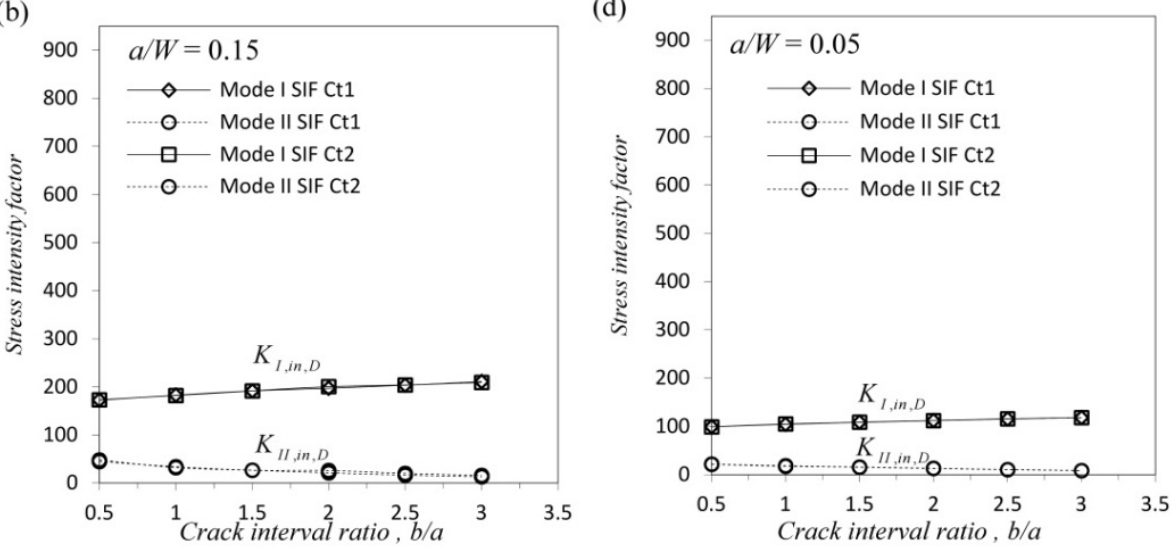

Figure 8. Variation of $K_{I, i n, D}$ and $K_{I,, i n, D}$ for $(a / W=0.05-0.2)$ 
From these figures, it also observed that the different between mode II SIF and mode I SIF is reduced as the $a / W$ decreases. In the context of crack interaction limit (CIL) based on $K_{I, i n, D}$ and $K_{I I, i n, D}$, by considering the convergence level as the indicator of CIL. It can be seen that the degree and speed of CIL achievement not only depends heavily on the increased of $b / a$, the reduction of $a / W$ from $a / W=0.5-0.05$ also provides significant impact on CIL determination.

Fig. 8 shows the variation of $K_{I, i n, D}$ and $K_{I I, i n, D}$ for $(a / W=0.05-0.2)$. It can be observed that at smallest $a / W=0.05$, the value of $K_{I, i n, D}$ and $K_{I I, i n, D}$ is almost hold at constant value and stabilize.

The identification of CIL in this condition is absent because the value of $K_{I, i n, D}$ and $K_{I I, i n, D}$ are about the same value for all $b / a$. This equalization condition may be referred to the identification of crack unification limit (CIL). Overall, it can be concluded that the higher ratio of $b / a$ and $a / W$, the more the realization of CIL. Inversely, the lower ratio of $b / a$ and $a / W$, the more indication to CUL can be realized.

\section{Conclusion}

The numerical solution based on displacement extrapolation method (DEM) has proved to be more consistent in SIF prediction comparedd to for both crack tips. However, the DEM able to predict the SIF for Mode I and Mode II fracture behaviour. The FE results conclude that the interaction of two cracks is directly influence the reduction of SIF magnitude and $\gamma_{I}$ at the crack tips. The parallel cracks have experienced decrease shielding effect as the cracks interval b/a decrease. The identification of crack interaction limit (CIL) and crack unification limit (CUL) has been accomplished. The SIF of Mode I is found more significant compared to Mode II in higher or lower $b / a$ and $a / W$ ratio. Mode II SIF can be neglected due to its small effect to the stress shielding effect. The FFS codes rules that define the combination of two cracks as single crack are well translated as CIL and CUL.

\section{Author details}

Ruslizam Daud, Ahmad Kamal Ariffin, Shahrum Abdullah and Al Emran Ismail Universiti Kebangsaan Malaysia, Malaysia

\section{References}

Andersson, B., Blom, A. F., Falk, U., Wang.G.S, Koski, K., Siljander, A., et al. (2009). A case study of multiple site fatigue crack growth in the F-18 Hornet bulkhead. Paper presented at the 25th ICAF Symposium.

ASME. (1998). ASME Boiler and Pressure Vessel Code, Section XI. New York, USA. 
ASME. (2004). ASME Boiler and Pressure Vessel Code, Section XI. New York, USA.

ASME. (2007). 579-1 / FFS-1 Fitness-for-service, Section 9, American Society of Mechanical Engineers. New York, USA.

Banks-Sills, L. (1991). Application of the Finite Element Method to Linear Elastic Fracture Mechanics. Appl. Mech. Rev, 44, 447-461.

Banks-Sills, L. (2010). Update: Application of the Finite Element Method to Linear Elastic Fracture Mechanics. Appl. Mech. Rev, 63, 1-17.

Barsoum, R. S. (1974). Application of Quadratic Isoparametric Finite Elements in Linear Fracture Mechanics. International Journal of Fracture, 10, 603-605.

Barsoum, R. S. (1975). Further application of quadratic isoparametric finite element to linear fracture mechanics of plate bending and general rules. International Journal of Fracture, 11, 167-169.

Barsoum, R. S. (1976). Application of Triangular Quarter-Point Elements as Crack Tip Elements of Power Law Hardening Material. International Journal of Fracture, 12, 463-466.

Brown, W. F., \& Strawley, J. E. (1966). ASTM STP 410.

BSI. (1991). British Standard Institute, PD 6493, Section 8. Guidance on methods for assessing the acceptability of flaws in fusion welded structures.

BSI. (1997). British Standard Institute, BS7910, Section 8. Guidance on methods for assessing the acceptability of flaws in structures.

BSI. (2005). British Standard Institute, BS7910. Guidance on methods for assessing the acceptability of flaws in metallic structures.

Burdekin, F. M. (1982). The role of fracture mechanics in the safety analysis of pressure vessels. Int. J. Mech. Sci., 24(4), 197-208.

Chandrupatla, T. R., \& Belegundu, A. D. (2002). Introduction to Finite Elements in Engineering (3rd ed.): Prentice Hall.

Chang, J. I., \& Lin, C.-C. (2006). A study of storage tank accidents. Journal of Loss Prevention in the Process Industries, 19, 51-59.

Chen, Y. Z., \& Liu, H. Y. (1988). Multiple cracks in pressurized hollow cyclinder. Theoritical and Applied Fracture Mechanics, 10, 213-218.

Garwood, S. J. (2001). Investigation of the MV Kurdistan casuality. Engineering Failure Analysis, 4(1), 3-24.

Gorbatikh, L., \& Kachanov, M. (2000). A simple technique for constructing the full stress and displacement fields in elastic plates with multiple cracks. Engineering Fracture Mechanics, 66, 51-63.

Henshell, R. D., \& Shaw, K. G. (1975). Crack tip finite elements are unnecessary. Int J Numer Engng, 9, 495-507.

Hu, W., Liu, Q., \& Barter, S. (2009). A study of interaction and coalescence of micro surface fatigue cracks in aluminium 7050. Paper presented at the 25th ICAF Symposium.

Ikeda, T., Nagai, M., Yamanaga, K., \& Miyazaki, N. (2006). Stress intensity factor analyses of interface cracks between dissimilar anisotropic materials using the finite element method. Engineering Fracture Mechanics, 73, 2067-2079.

Isida, M. (1973). Analysis of stress intensity factors for the tension of a centrally cracked strip with stiffened edges. Engineering Fracture Mechanics, 5, 647-665. 
Jeong, D. Y., \& Brewer, J. C. (1995). On the linkup of multiple cracks. Engineering Fracture Mechanics, 51(2), 233-238.

Jones, R., Peng, D., \& Pitt, S. (2002). Assessment of multiple flat elliptical cracks with interactions. Theoretical and Applied Fracture Mechanics, 38, 281-291ssss.

JSME. (2000). JSME Fitness-for-Service Code S NA1-2000.

JSME. (2008). JSME Fitness-for-Service Code S NA1-2008.

Kamaya, M. (2003). A crack growth evaluation method for interacting multiple cracks. JSME International Journal, 46(1), 15-23.

Kamaya, M. (2008a). Growth evaluation of multiple interacting surface cracks. Part II: Growth evaluation of parallel cracks. Engineering Fracture Mechanics, 75, 1350-1366.

Kamaya, M. (2008b). Growth evaluation of multiple interacting surface cracks.Part I: Experiments and simulation of coalesced crack. Engineering Fracture Mechanics, 75, 13361349.

Kamaya, M., Miyokawa, E., \& Kikuchi, M. (2010). Growth prediction of two interacting surface cracks of dissimilar sizes. Engineering Fracture Mechanics, 77, 3120-3131.

Kirkhope, K. J., Bell, R., \& Kirkhope, J. (1991). Stress intensity factors for single and multiple semi-elliptical surface cracks in pressurized thick-walled cylinders. International Journal of Pressure Vessel and Piping, 47, 247-257.

Kobayashi, H., \& Kashima, K. (2000). Overview of JSME flaw evaluation code for nuclear power plants. International Journal of Pressure Vessels and Piping, 77, 937-944.

Lakes, R. S., Nakamura, S., Behiri, J. C., \& Bonfield, W. (1990). Fracture mechanics of bone with short cracks. J. Biomechanics, 23(10), 967-975.

Lam, K. Y., \& Phua, S. P. (1991). Multiple crack interaction and its effect on stress intensity factor. Engineering Fracture Mechanics, 40(3), 585-592.

Leek, T. H., \& Howard, I. C. (1994). Estimating the elastic interaction factor of two coplanar surface cracks under Mode I load. International Journal of Pressure Vessels and Piping, 60, 307-321.

Leek, T. H., \& Howard, I. C. (1996). An examination of methods of assessing interacting surface cracks by comparison with experimental data. International Journal of Pressure Vessels and Piping, 68, 181-201.

Lewis, P. R., \& Weidmann, G. W. (2001). Catastropic failure of a polypropylene tank Part I: primary investigation. Engineering Failure Analysis, 6(4), 197-214.

Madenci, E., \& Guven, I. (2006). The finite element method and application in engineering using ANSYS (1 ed.): Springer Science-Business.

Matake, T., \& Imai, Y. (1977). Pop-in behaviour induced by interaction of cracks. Engineering Fracture Mechanics, 9, 17-24.

Meizoso, A. M., Esnaola, J. M. M., \& Perez, M. F. (1995). Interaction effect of multiple crack growth on fatigue. Theoretical and Applied Fracture Mechanics, 23, 219-233.

Milwater, H. R. (2010). A simple and accurate method for computing stress intensity factors of collinear interacting cracks. Aerospace Science and Technology.

Mischinski, S., \& Mural, A. (2011). Finite Element Modeling of Microcrack Growth in Cortical Bone. Journal of Applied Mechanics, 78, 1-9. 
Moussa, W. A., Bell, R., \& Tan, C. L. (1999). The interaction of two parallel non-coplanar identical surface cracks under tension and bending. International Journal of Pressure Vessels and Piping, 76, 135-145.

Murakami, Y. (1976). A simple procedure for the accurate determination of stress intensity factors by finite element method. Engineering Fracture Mechanics, 8, 643-655.

Murakami, Y., \& Nasser, S. N. (1982). Interacting dissimilar semi-elliptical surface flaws under tension and bending. Engineering Fracture Mechanics, 16(3), 373-386.

Newman, J. A., Baughman, J. M., \& Wallace, T. A. (2010). Investigation of cracks found in helicopter longerons. Engineering Failure Analysis, 17, 416-430.

Newman, J. C., \& Raju, I. S. (1981). An empirical stress intensity factor equation for the surface cracks. Engineering Fracture Mechanics, 15, 185-192.

O'donoghue, P. E., Nishioka, T., \& Atluri, S. N. (1984). Multiple surface cracks in pressure vessel. Engineering Fracture Mechanics, 20(3), 545-560.

Pant, M., Singh, I. V., \& Mishra, B. K. (2011). A numerical study of crack interactions under thermo-mechanical load using EFGM. Journal of Mechanical Science and Technology 25(2), 403-413.

Park, C. H., \& Bobet, A. (2010). Crack initiation, propagation and coalescence from frictional flaws in uniaxial compression. Engineering Fracture Mechanics, 77, 2727-2748.

Parker, A. P. (1999). Stability of arrays of multiple edge cracks. Engineering Fracture Mechanics, 62, 577-591.

Pitt, S., Jones, R., \& Atluri, S. N. (1999). Further studies into interacting 3D cracks. Computers and Structures, 70, 583-597.

R6. (2006). Nuclear Electric : Assessment of the integrity of structures containing defects, Revision 4. Gloucester, British Energy Generation Ltd.

Ratwani, M., \& Gupta, G. D. (1974). Interaction between parallel cracks in layered composites. International Journal of Solids and Structures, 10, 701-708.

Rutti, T. F., \& Wentzel, E. J. (1997). Investigation of failed actuator piston rods. Engineering Failure Analysis, 5(2), 91-98.

Saha, T. K., \& Ganguly, S. (2005). Interaction of penny-shaped cracks with an eliptic crack under shear loading. International Journal of Fracture, 131, 267-287.

Sankar, R., \& Lesser, A. J. (2006). Generic Overlapping Cracks in Polymers: Modeling of Interaction. International Journal of Fracture, 142, 277-287.

Sekhtar, A. S. (2008). Multiple cracks effects and identification. Mechanical Systems and Signal Processing, 22, 845-878.

Shields, E. B., Srivatsan, T. S., \& Padovan, J. (1992). Analytical methods for evaluation of stress intensity factors and fatigue crack growth. Engineering Fracture Mechanics, 42(1), 126.

Shivakumar, K. N., \& Raju, I. S. (1992). An equivalent domain integral method for threedimensional mixed-mode fracture problems. Engineering Fracture Mechanics, 42, 935-959.

Ural, A., Zioupos, P., Buchanan, D., \& Vashishth, D. (2011). The effect of strain rate on fracture toughness of human cortical bone: A finite element study. Journal of the Mechanical Behaviour of Biomedical Materials. 
Weidmann, G. W., \& Lewis, P. R. (2001). Catastropic failure of a polypropylene tank Part II: comparison of the DVS 2205 code of practice and the design of the failed tank. Engineering Failure Analysis, 6(4), 215-232.

Xuan, F.-Z., Si, J., \& Tu, S. T. (2009). Evaluation of $C^{*}$ integral for interacting cracks in plates under tension. Engineering Fracture Mechanics, 76, 2192-2201.

Yang, Y. H. (2009). Multiple parallel symmetric mode III cracks in a functionally graded material plane. Journal of Solid Mechanics and Materials Engineering, 3(5), 819-830.

Z.D.Jiang, A.Zeghloul, G.Bezine, \& J.Petit. (1990). Stress intensity factor of parallel cracks in a finite width sheet. Engineering Fracture Mechanics, 35(6), 1073-1079.

Z.D.Jiang, J.Petit, \& G.Bezine. (1990). Fatigue propagation of two parallel cracks. Engineering Fracture Mechanics, 37(5), 1139-1144. 